\title{
High phosphate diet reduces atherosclerosis formation in apolipoprotein E-deficient mice
}

\author{
Asuka Shiota, ${ }^{1}$ Yutaka Taketani, ${ }^{1, *}$ Yoichi Maekawa, ${ }^{2}$ Koji Yasutomo, ${ }^{2}$ Masataka Sata, ${ }^{3}$ Tohru Sakai, $^{4}$ \\ Risuke Mizuno, ${ }^{5}$ Masashi Isshiki, ${ }^{5}$ Hironori Yamamoto ${ }^{1}$ and Eiji Takeda ${ }^{1}$ \\ 'Department of Clinical Nutrition, Institute of Health Biosciences, the University of Tokushima Graduate School, and \\ 2Department of Immunology and Parasitology, Institute of Health Biosciences, the University of Tokushima Graduate School, and \\ ${ }^{3}$ Department of Cardiovascular Medicine, Institute of Health Biosciences, the University of Tokushima Graduate School, and \\ ${ }^{4}$ Department of Public Health and Applied Nutrition, Institute of Health Biosciences, the University of Tokushima Graduate School, \\ 3-18-15 Kuramoto-cho, Tokushima 770-8503, Japan \\ ${ }^{5}$ Department of Molecular Vascular Endocrinology, Graduate School of Medicine, University of Tokyo, Tokyo 113-0033, Japan
}

(Received 25 December, 2010; Accepted 4 January, 2011; Published online 25 May, 2011)

\begin{abstract}
Although higher serum phosphate level is a risk factor for cardiovascular diseases in general population as well as chronic kidney disease patients, it has not been clarified whether higher phosphate can affect atherosclerotic plaque formation. In this study, we investigated the effect of prolonged-intake of different concentrations of phosphate on atherosclerosis formation using apolipoprotein E-deficient mice. Apolipoprotein E-deficient mice were fed with high fat diet including $0.6 \%, 1.2 \%$ or $1.8 \%$ phosphate. After 20-week treatment, atherosclerotic plaque formation in aorta in $1.8 \%$ phosphate diet group was unexpectedly less than that in the other groups. To elucidate mechanisms of suppression of plaque formation by high phosphate diet, we hypothesized that high phosphate diet may modify a profile of monocytes/ macrophages suppressing plaque formation. We confirmed that elevated peripheral monocytes (CD11b+, F4/80+ cell numbers) in apolipoprotein E-deficient mice were decreased by feeding with $1.8 \% \mathrm{P}$ diet. In addition, ex vivo study indicated that high dose of phosphate induced macrophage apoptosis. These observations suggest that excess phosphate intake decreased atherosclerosis formation, at least in part, by changing the profile of peripheral monocytes or inducing apoptosis of macrophages in apolipoprotein E-deficient mice.
\end{abstract}

Key Words: hyperphosphatemia, atherosclerogenesis, apoptosis, macrophage, chronic kidney disease

$\mathrm{H}$ igher serum phosphate $(\mathrm{P})$ level, even within the normal range, has been reported as a risk factor for cardiovascular diseases (CVDs) in recent epidemiological researches. ${ }^{(1,2)}$ It has been thought to be a possible mechanism that excessive serum $\mathrm{P}$ can induce vascular calcification. ${ }^{(3-5)}$ On the other hand, there are a few reports describing relationship between serum $P$ levels and carotid intima-media thickness, which are used as an indicator of progression of atherosclerosis. ${ }^{(6-8)}$ However, it is unknown whether hyperphosphatemia or high $\mathrm{P}$ diet intake can induce atherosclerosis or not.

Atherosclerosis is a chronic inflammatory disease in artery, and caused by complicated pathogenesis. Both endothelial dysfunction and infiltrating macrophages in sub intimal layer are primary pathogenic mechanisms for the development of atherosclerosis. ${ }^{(9)}$ Indeed, reducing inflammation by nonsteroidal anti-inflammatory drugs can reduce plaque formation in early to intermediate stage of atherosclerosis. ${ }^{(10)}$ To date, several animal models have been established to understand the relationship between risk factors and atherosclerogenesis. Hypercholesterolemic apolipoprotein E (ApoE)-deficient mouse is a useful model for studying about atherosclerosis. It has been reported that increased oxidative stress inactivated nitric oxide (NO) responsible for endothelial dysfunction. ${ }^{(11-13)}$ Furthermore, inhibition of NO synthesis aggravated atherosclerotic plaque formation in ApoE-deficient mice. ${ }^{(14,15)}$ In our previous study, we demonstrated that high dose $\mathrm{P}$ loading induced endothelial dysfunction by increasing oxidative stress and decreasing NO production ex vivo and in vitro. ${ }^{(16)}$ Thus we hypothesized that higher $\mathrm{P}$ intake can increase serum $\mathrm{P}$ levels, and accelerate atherosclerotic plague formation by aggravating endothelial dysfunction in ApoE-deficient mice. In this study, we examined the effects of different amount of $\mathrm{P}$ intake on progression of atherosclerosis in ApoE-deficient mice.

\section{Materials and Methods}

Mice. 5-week-old male C57BL/6.KOR/StmSlc-ApoE ${ }^{\text {shl }}$ and C57BL/6 mice were obtained from Japan SLC (Shizuoka, Japan). After 1 week of adaptation, mice were divided and fed a westerntype diet $(20 \%$ Fat; $0.15 \%$ cholesterol $(\mathrm{w} / \mathrm{w}))$ containing $0.6 \%$ calcium, and $0.6 \%, 1.2 \%$ or $1.8 \%$ phosphorus $(\mathrm{w} / \mathrm{w})$ respectively for 7 weeks for flow cytometry or 20 weeks for atherosclerotic formation analysis. All procedures were approved by the guidelines for animal experimentation of the University of Tokushima.

Plasma and urinary analysis. A blood sample was obtained via abdominal inferior vena cava with heparin, immediately centrifuged at 10,000 rpm for $3 \mathrm{~min}$ at room temperature and the plasma was stored at $-80^{\circ} \mathrm{C}$ until measurement. Urine was collected over a 24-h period and was also stored at $-80^{\circ} \mathrm{C}$ until measurement. Total-Cholesterol (T-Cho), triglycerides (TG), inorganic P, $\mathrm{Ca}$ and creatinine levels in the plasma and/or urine were measured by using commercially available kits (Wako Pure Chemical Industries, Ltd., Osaka, Japan). ELISA was performed for measuring plasma FGF23 (KAINOS LABORATORIES, Inc., Tokyo, Japan), intact parathyroid hormone (iPTH) (Immunotopics International, San Clemente, CA) and MCP-1 (Thermo Fisher Scientific, Inc., Rockford, IL). Tissue plasminogen activator inhibitor-1 (tPAI-1), interleukin-6 (IL-6) and tumor necrosis factor- $\alpha$ (TNF$\alpha$ ) were measured with a mouse adipokine plasma multiplex assay system (Millipore Japan, Tokyo, Japan). 1,25-dihydroxyvitamin D $\left(1,25-(\mathrm{OH})_{2} \mathrm{D}\right)$ was measured by the radioreceptor assay (SRL, Inc., Tokyo, Japan).

en face aorta analysis. The aorta was perfused with phosphate buffered saline (PBS) from the left ventricle of the heart and

*To whom correspondence should be addressed.

E-mail: taketani@nutr.med.tokushima-u.ac.jp 
Table 1. Fasting blood and urine chemistry relating on $P, C a$ and lipid metabolisms, and kidney function in ApoE-deficient mice fed with high fat diet for 20 weeks. Plasma was collected after overnight fast. Urine was collected for $24 \mathrm{~h}$. All urinary markers were normalized by creatinine. TG; triacylglyceride, T-Cho; total cholesterol, Crea; creatinine. Values shown are means \pm SD. ${ }^{\star} p<0.05$ vs $0.6 \% \mathrm{P},{ }^{*} p<0.05$ vs $1.2 \% \mathrm{P}$.

\begin{tabular}{llccc}
\hline & & $0.6 \% \mathrm{P}$ & $1.2 \% \mathrm{P}$ & $1.8 \% \mathrm{P}$ \\
\hline Plasma & & & $1.35 \pm 0.24$ \\
$\mathrm{P}$ & $(\mathrm{mmol} / \mathrm{l})$ & $1.55 \pm 0.17$ & $1.52 \pm 0.17$ & $2.15 \pm 0.16$ \\
Ca & $(\mathrm{mmol} / \mathrm{l})$ & $2.13 \pm 0.28$ & $2.17 \pm 0.25$ & $31.3 \pm 9.67$ \\
Intact PTH & $(\mathrm{pg} / \mathrm{ml})$ & $26.8 \pm 7.26$ & $35.8 \pm 17.3^{*}$ & $958 \pm 197 *$ ** \\
FGF23 & $(\mathrm{pg} / \mathrm{ml})$ & $138 \pm 23.6$ & $216 \pm 27.6$ & $51.5 \pm 8.84$ \\
1,25-(OH) $2 \mathrm{D}$ & $(\mathrm{pg} / \mathrm{ml})$ & $119 \pm 62.1$ & $88.8 \pm 32.5$ & $1.76 \pm 0.34$ \\
TG & $(\mathrm{mmol} / \mathrm{l})$ & $1.51 \pm 0.58$ & $1.84 \pm 0.38$ & $18.2 \pm 4.01$ \\
T-Cho & $(\mathrm{mmol} / \mathrm{l})$ & $16.3 \pm 3.85$ & $17.5 \pm 3.49$ & $136 \pm 18.4 *, * *$ \\
Urinary & & & & $0.82 \pm 0.45$ \\
P & $(\mathrm{mol} / \mathrm{mol}$ Crea $)$ & $45.8 \pm 11.2$ & $85.6 \pm 6.75 *$ & $0.55 \pm 0.17$ \\
Ca & $(\mathrm{mol} / \mathrm{mol}$ Crea) & $0.57 \pm 0.23$ & & \\
\hline
\end{tabular}

used for en face aorta analysis. The aorta from iliac bifurcation to aortic arch was removed and external fatty deposits outside the aorta were completely removed. The aorta was cut open by longitudinally and fixed with $4 \%(\mathrm{w} / \mathrm{v})$ formalin for $30 \mathrm{~min}$. After Rinsing in distilled water and $60 \%(\mathrm{v} / \mathrm{v})$ isopropanol, the specimen was stained with oil red $\mathrm{O}$ for $5 \mathrm{~min}$, and then rinsed in $60 \%(\mathrm{v} / \mathrm{v})$ isopropanol and distilled water. Picture was taken by TS-CA200M camera (SUGITOH Co., Ltd., Tokyo, Japan). Image analysis was performed with Image Pro Plus (version 6.0; Media Cybernetics, Bethesda, MD). The amount of lipid deposits in each sample was measured relative to total area.

Flow cytometry. Anti-mouse Gr-1 (Ly-6G) antibody conjugated with eFluor ${ }^{\circledR} 780$, anti-CD11b (M1/70) antibody conjugated with PE(phycoerythrin)-APC-Cy7 and anti-F4/80 (BM8) antibody conjugated with eFluor ${ }^{\circledR} 450$ were obtained from eBioscience, Inc. (San Diego, CA). Peripheral blood leucocytes $(500 \mu \mathrm{l}$ whole blood per a mouse) were collected via inferior vena cava and erythrocytes were lysed. Samples were incubated with Fc $\gamma \mathrm{III} / \mathrm{II}$ receptor $(2.4 \mathrm{G} 2)$ antibody to block nonspecific antibody binding for $15 \mathrm{~min}$ at $4^{\circ} \mathrm{C}$, stained with antibody mixture for $15 \mathrm{~min}$ at $4^{\circ} \mathrm{C}$ then stained for 7-amino-actinomycin D (7-AAD) (Sigma Aldrich Japan, Tokyo, Japan) to detect dead cells. Cells were analyzed on FACS Canto II (Japan Becton Dickinson, Tokyo, Japan). Up to 100,000 events were acquired.

Preparation of intraperitoneal macrophages. To collect the peritoneal macrophages, non-treatment C57BL/6 mice were injected i.p. with $4.05 \%$ (w/v) thioglycolate medium, and after 3 days, mice were euthanized and i.p. macrophages were collected with $0.9 \%(\mathrm{w} / \mathrm{v})$ saline. After washing with saline, macrophages were centrifuged for $5 \mathrm{~min}$ at $1,000 \mathrm{rpm}$, resuspended with Dulbecco's modified Eagle's medium (DMEM) including 10\% $(\mathrm{v} / \mathrm{v})$ of fetal calf serum (FCS) and seeded in 96-well plates $\left(5 \times 10^{4}\right.$ cells per well) for AlamarBlue assay and on coverslip in 24 -well plates $\left(5 \times 10^{5}\right.$ cells per well) for TUNEL staining. After incubation in humidified $37^{\circ} \mathrm{C}, 5 \%(\mathrm{v} / \mathrm{v}) \mathrm{CO}_{2}$ incubator for several hours, non-attached cells were removed then macrophages were used for each experiment.

AlamarBlue assay. Macrophages were starved fresh medium without FCS overnight and medium was changed $2 \mathrm{~h}$ before stimulation. To evaluate effect of phosphate concentrations in medium on cellular viability, macrophages were incubated with DMEM including $10 \%(\mathrm{v} / \mathrm{v})$ of AlamarBlue reagent (Invitrogen Japan, Tokyo, Japan) for $4 \mathrm{~h}$. We added appropriate amounts of sodium phosphate buffer $\left(0.1 \mathrm{M} \mathrm{Na}_{2} \mathrm{HPO}_{4} / \mathrm{NaH}_{2} \mathrm{PO}_{4}, \mathrm{pH} 7.4\right)$. Delta absorbance (570-600 nm) was measured.

TUNEL staining. Apoptosis in situ detection kit (Wako) was used for TUNEL assay. Macrophages on coverslip were fixed with $4 \%(\mathrm{w} / \mathrm{v})$ formalin and permeablized with permeablization solution $(0.1 \%(\mathrm{w} / \mathrm{v})$ sodium citric acid and $0.1 \%(\mathrm{v} / \mathrm{v})$ Triton X100). Applying TdT reaction solution for $10 \mathrm{~min}$ at $37^{\circ} \mathrm{C}$, washing with PBS, peroxidase (POD)-conjugated antibody for $10 \mathrm{~min}$ at $37^{\circ} \mathrm{C}$, washing with PBS then positive staining cells were visualized with diaminobenzidine (DAB) solution.

Statistical analysis. All data were expressed as the means \pm SD. Statistical analysis was analyzed with student's $t$ test for non-parametric comparison between two groups, or analysis of variance (ANOVA) with post hoc test by Fisher's protected least significant difference (PLSD) test for multiple comparisons. $p<0.05$ was considered significant.

\section{Results}

Effects of prolonged higher $P$ intake on Ca-P and lipid metabolisms. ApoE-deficient mice were fed with western diet including $0.6 \% \mathrm{Ca}$, and $0.6 \%, 1.2 \%$ or $1.8 \% \mathrm{P}$ for 20 weeks. In normal condition, serum $\mathrm{Ca}$ and $\mathrm{P}$ concentrations are strictly regulated by parathyroid hormone (PTH), Fibroblast growth factor 23 (FGF23) and 1,25-(OH) 2 D, thus excess $P$ can be immediately excreted into the urine. To confirm effects of prolonged much amount of $\mathrm{P}$ intake on kidney function and mineral metabolism in ApoE-deficient mice, we assayed plasma and urinary concentrations of markers related on Ca and $\mathrm{P}$ metabolisms. All groups did not show any significant difference in plasma $\mathrm{P}$, and plasma and urinary $\mathrm{Ca}$ levels while urinary $\mathrm{P}$ level corrected by creatinine in $1.8 \% \mathrm{P}$ group was significantly higher than that in the other groups (Table 1). Plasma intact PTH level in $1.2 \% \mathrm{P}$ group was significantly higher than that in $0.6 \% \mathrm{P}$ group, and plasma FGF23 in $1.8 \% \mathrm{P}$ group was significantly higher than that in the other groups but plasma $1,25-(\mathrm{OH})_{2} \mathrm{D}$ levels in all groups were not significantly different. Considering all various markers together, $\mathrm{Ca}$ and $\mathrm{P}$ metabolisms were normally regulated in ApoE-deficient mice in response to dietary $\mathrm{P}$ modifications.

As abnormal blood lipids are important risk factors for atherosclerosis, we examined effects of different amount of $P$ intake on lipid metabolism. There was no significant difference among groups on plasma TG and T-Cho levels. Therefore, dietary $\mathrm{P}$ intake did not affect blood lipid concentrations in ApoE-deficient mice.

Atherosclerotic formation in aorta and atherosclerotic indicators in plasma. We evaluated atherosclerotic plaque formation by staining enface aorta with Oil red O. Despite our hypothesis which higher $\mathrm{P}$ intake can progress atherosclerotic formation, surprisingly, $1.8 \% \mathrm{P}$ intake significantly suppressed the development of atherosclerotic plaque compared with lower $\mathrm{P}$ intake (Fig. 1a). Especially, lesions in thoracic and abdominal aorta decreased in $1.8 \% \mathrm{P}$ group. 

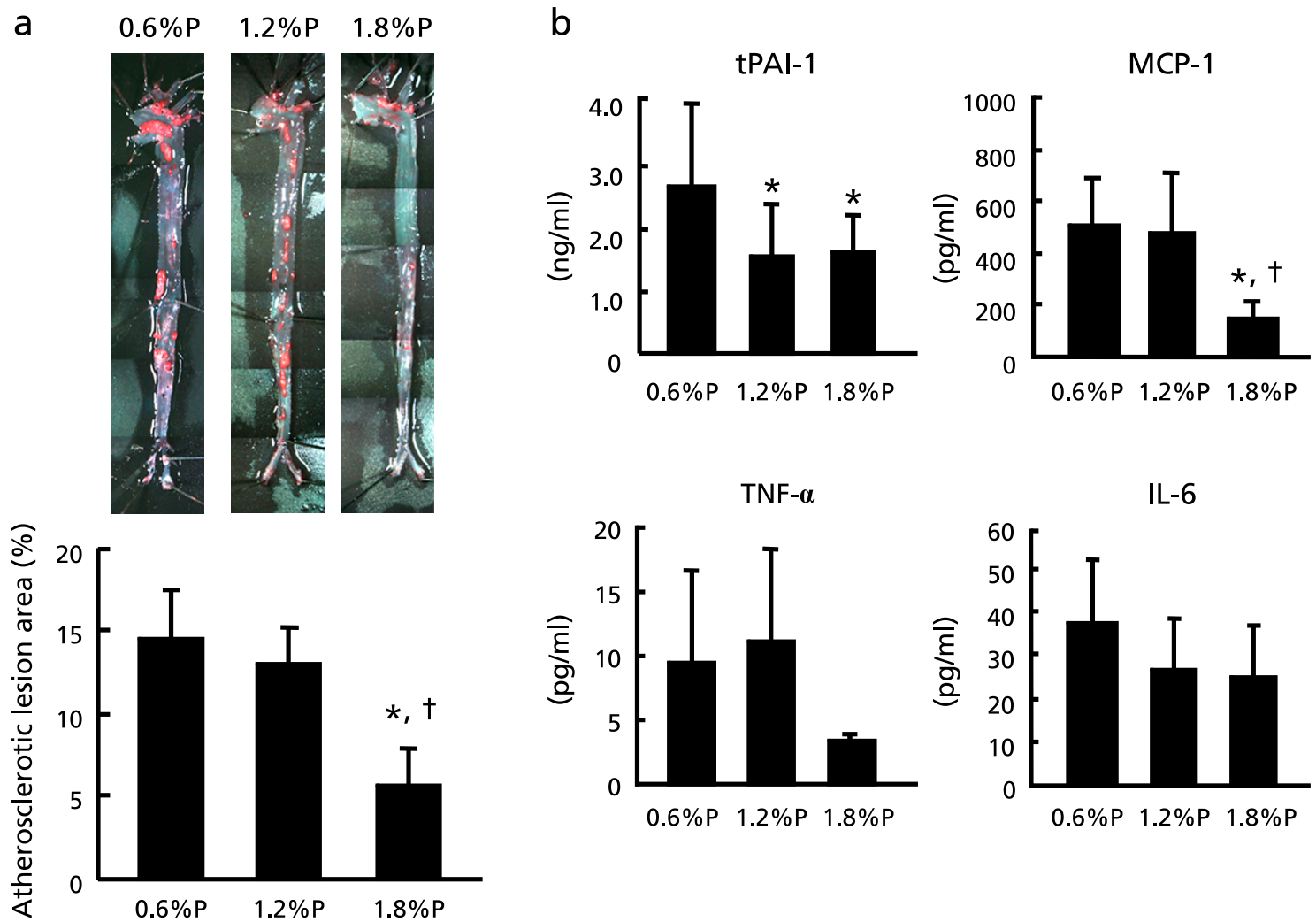

Fig. 1. Atherosclerotic lesion area and plasma cytokine levels in ApoE-deficient mice fed with high fat diet for 20 weeks. (a) Whole aortas were stained with Oil red $\mathrm{O}$ to reveal lipid deposits and atherosclerotic lesion area was quantitated as the ratio of the total lipid deposits area to the total surface area. (b) Tissue plasminogen activator inhibitor 1 (tPAl-1), monocyte chemotactic protein-1 (MCP-1), Tumor necrosis factor- $\alpha$ (TNF- $\alpha$ ), Interleukin-6 (IL-6) were measured as atherosclerotic indicators. Values shown are means \pm SD. ${ }^{*} p<0.05$ vs $0.6 \%$, ${ }^{\dagger} p<0.05$ vs $1.2 \%$.

To elucidate the mechanism of suppression of atherosclerosis formation in $1.8 \% \mathrm{P}$ group, we analyzed plasma tissue plasminogen activator inhibitor-1 (tPAI-1), monocyte chemoattractant protein-1 (MCP-1), tumor necrosis factor- $\alpha(\mathrm{TNF}-\alpha)$ and interleukin-6 (IL-6) concentrations. Plasma tPAI-1 levels were significantly decreased in $1.2 \% \mathrm{P}$ and $1.8 \% \mathrm{P}$ groups compared with $0.6 \% \mathrm{P}$ group (Fig. 1b). Plasma MCP-1 levels were significantly decreased in $1.8 \% \mathrm{P}$ group compared with the other groups. Plasma TNF- $\alpha$ and IL-6 did not show any significant difference among all groups.

Dietary phosphate affected peripheral blood monocytes in vivo. As shown above, high $\mathrm{P}$ diet intake unexpectedly suppressed atherosclerosis formation. Next we investigated effect of dietary $\mathrm{P}$ intake on peripheral blood monocytes, because monocyte recruitment is a primary event for atherosclerogenesis. We fed ApoE-deficient and C57BL/6, as a control, mice with high fat diet including $0.6 \%$ or $1.8 \%$ phosphorus for 7 weeks and the blood leukocytes were analyzed by flow cytometry. Intraperitoneal $\mathrm{CD} 11 \mathrm{~b}$ positive and F4/80 positive cells, which indicate monocytes, were significantly increased in ApoE- $0.6 \% \mathrm{P}$ group than C57BL/6-0.6\% P (WT-0.6\% P) group (Fig. 2). On the other hand, the cell numbers in ApoE-1.8\% $\mathrm{P}$ group were reduced as same as that in WT- $0.6 \% \mathrm{P}$ group.

Effects of $P$ intake on intraperitoneal macrophage apoptosis in vitro. As reason for alteration of peripheral blood monocyte cellularity, we took into considerations of effects of dietary $\mathrm{P}$ intake on haematocyte differentiation and/or monocyte apoptosis. In this study, we investigated whether dietary P intake can induce monocyte apoptosis; because there are several reports which higher dose $\mathrm{P}$ stimulation can induce apoptosis in some cell lines, such as endothelial cells, osteoblasts and chondrocytes. ${ }^{(17-19)}$ First, we used AlamarBlue reagent to assess whether extracellular

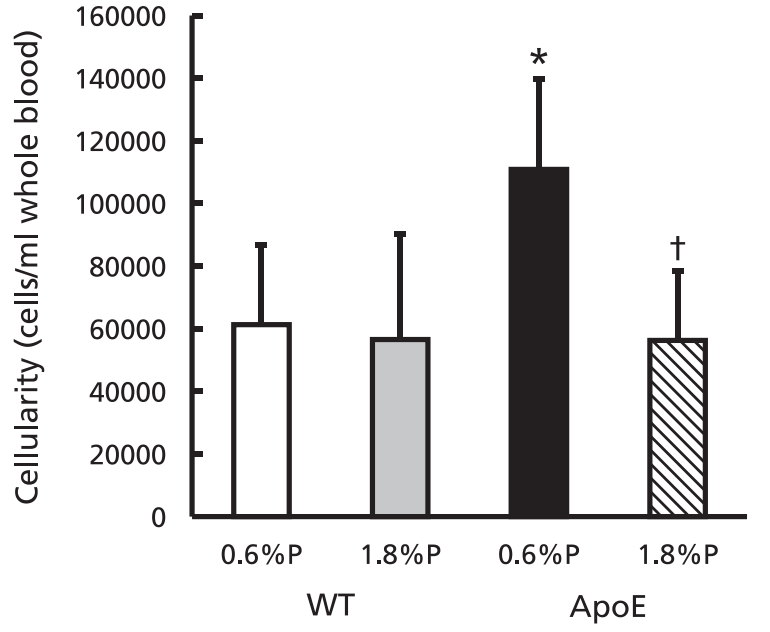

Fig. 2. F4/80 positive cell numbers in peripheral leukocytes of WT (C57BL/6) and ApoE-deficient mice fed with high fat diet for 7 weeks. Peripheral leukocytes were labeled with anti-CD11b antibody conjugated with PE-Cy7 and anti-F4/80 antibody conjugated with eFluor ${ }^{\circledR} 450$ to determine the number of monocytes and analyzed by flow cytometry. Values shown are means \pm SD. ${ }^{*} p<0.05$ vs WT- $0.6 \% \mathrm{P}^{+}{ }^{+} p<0.05$ vs ApoE$0.6 \%$ P.

$\mathrm{P}$ concentrations can affect macrophage viability. High $\mathrm{P}$ loading dose-dependently decreased the metabolic activity of thioglycolateelicited macrophages (Fig. 3a). Since ApoE-deficient mice show 
a

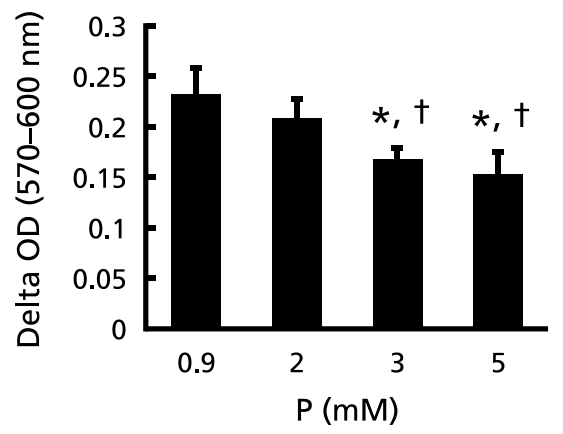

b
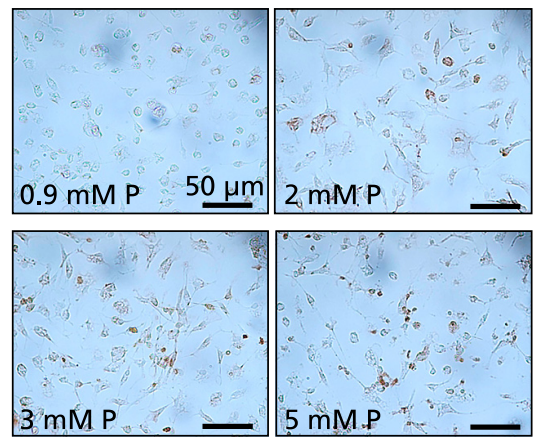

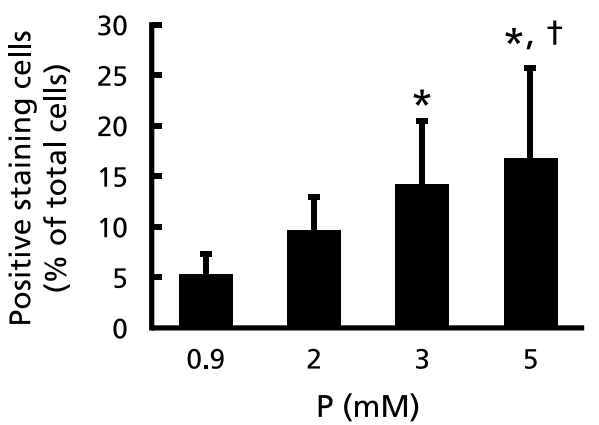

Fig. 3. Effects of $P$ on thioglycolate-elicited macrophages. (a) Thioglycolate-elicited intraperitoneal macrophages from WT mice were stimulated with different concentrations of $\mathrm{P}$, and their cellular metabolic activity was measured with AlamarBlue reagent. Metabolic activity of cells was expressed as delta OD (570-600 nm). (b) Cells were stimulated with different concentrations of $P$ under oxidative stress condition (0.05 mM hydrogen peroxide). Apoptotic cells were detected by TUNEL. TUNEL positive staining cell numbers were corrected by total cell numbers in the field of vision. Values shown are means \pm SD. ${ }^{*} p<0.05$ vs $0.9 \mathrm{mM},{ }^{+} p<0.05$ vs $2 \mathrm{mM}$.

increased oxidative stress, ${ }^{(20)}$ thioglycolate-elicited macrophages were stimulated by high $\mathrm{P}$ loading under oxidative stress condition, and apoptosis was analyzed by TUNEL staining to confirm whether high concentrations of $\mathrm{P}$ can stimulate macrophage apoptosis. Macrophage apoptosis was enhanced by high $\mathrm{P}$ loading under oxidative stress (Fig. 3b).

$1.8 \% \mathrm{P}$ diet intake decreased $\mathrm{F} 4 / 80+, \mathrm{Gr}-1+$ cells in peripheral blood in ApoE-deficient mice. Activation of monocytes plays an important role in the development of atherosclerosis. Peripheral leukocytes from 7-week fed ApoE-deficient and C57BL/6 mice were analyzed by flow cytometry. We found that CD11b positive, F4/80 positive and Gr-1 positive cells (including inflammatory monocytes) were 2-fold as large as Gr-1 negative cells (resident monocytes) in ApoE- $0.6 \% \mathrm{P}$ group but not the other groups (Fig. 4).

\section{Discussion}

Inhibition of NO production aggravated atherosclerosis in ApoE-deficient mice. ${ }^{(14,15)}$ Excess P loading can induce endothelial dysfunction by decreasing endothelial nitric oxide production, ${ }^{(16)}$ increasing oxidative stress, ${ }^{(16,17)}$ or inducing apoptosis. ${ }^{(17)}$ Therefore, we hypothesized that $\mathrm{P}$ loading can synergistically aggravated atherosclerosis in ApoE-deficient mice, however, excessive $\mathrm{P}$ intake ameliorated atherosclerosis in aorta in ApoE-deficient mice, unexpectedly.

We considered that the unexpected effect of high $\mathrm{P}$ loading on the development of atherosclerosis must be independent on endothelial dysfunction. Because, there was no significant difference between $1.8 \% \mathrm{P}$ diet and $0.6 \% \mathrm{P}$ diet groups in acetylcholinedependent vasodilation of thoracic aortic ring in ApoE-deficient mice (our unpublished observation). The observation suggests that

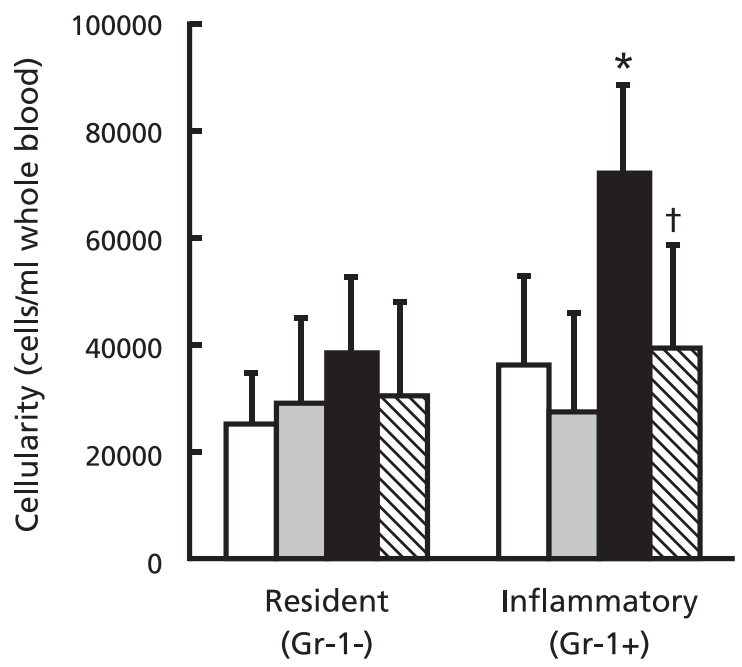

Fig. 4. Gr-1 (LY-6G) positive or negative cell numbers in peripheral leukocytes of WT (C57BL/6) and ApoE-deficient mice fed with high fat diet for 7 weeks. Peripheral leukocytes were labeled with anti-CD11b antibody conjugated with $\mathrm{Cy} 7$, anti-F4/80 antibody conjugated with eFluor ${ }^{\circledR} 450$ and anti-Gr-1 (LY-6G) antibody conjugated with eFluor ${ }^{\circledR 780}$ to determine the number of resident monocytes (Gr-1 negative) and inflammatory monocytes (Gr-1 positive) and analyzed by flow cytometry. Open column; WT- $0.6 \%$ P, dotted column; WT-1.8\% P, closed column; ApoE- $0.6 \%$ P, hatched column; ApoE- $1.8 \%$ P. Values shown are means \pm SD. ${ }^{*} p<0.05$ vs WT- $0.6 \% \mathrm{P}^{+}{ }^{\dagger} p<0.05$ vs ApoE- $0.6 \% \mathrm{P}$ 
endothelial function in ApoE-deficient mice has been impaired as shown in previous study, ${ }^{(21)}$ and dietary $\mathrm{P}$ intake did not additionally affect endothelial function. Generally, recruitment and migration of monocytes across endothelium are very important events as much as endothelial dysfunction in atherosclerosis formation. Liu et al. reported that reduction of macrophage apoptosis accelerated atherosclerosis. $^{(22)}$ In addition, other researchers demonstrated that macrophage apoptosis in early stage of atherosclerosis development was very efficient and diminished plaque formation but not advanced stage. ${ }^{(23-25)}$ Therefore, we investigated the effect of high P loading on monocytes/macrophages.

In this study, we demonstrated that peripheral CD11b+, F4/80+ cell numbers were decreased by $1.8 \% \mathrm{P}$ intake compared with $0.6 \% \mathrm{P}$ in ApoE-deficient mice and high concentrations of dietary $\mathrm{P}$ induced thioglycolate-elicited macrophage apoptosis under oxidative stress condition. These effects suggest that the effect of excess $\mathrm{P}$ intake on peripheral blood would be anti-atherosclerogenesis by inducing monocyte/macrophage apoptosis under oxidative condition.

Recent studies reported that blood monocytes include two functional subsets, inflammatory and resident monocytes. ${ }^{(26-28)}$ Despite no significant difference between atherosclerosis formation at the time of 7 -week feeding with $0.6 \%$ or $1.8 \% \mathrm{P}$ diet (data were not shown), excess $\mathrm{P}$ intake reduced only inflammatory monocytes in peripheral blood. However, we could not determine whether P induced apoptosis in inflammatory monocytes or affected monocytes subsets. The changed profile of monocytes may account for the decreases in inflammatory and atherosclerogenic factors such as tPAI-1, MCP-1, TNF- $\alpha$ in ApoE-deficient mice fed with $1.8 \% \mathrm{P}$ diet. In addition, the decreases in those inflammatory and atherosclerogenic factors may have a protective effect on atherosclerogenesis by suppressing endothelial dysfunction. Because previous studies have reported that deficiency of MCP-1, TNF- $\alpha$ or PAI-1 reduced atherosclerosis formation, ${ }^{(29-32)}$ and have indicated that these cytokines play an important role in plaque progression. Thus, these possible mechanisms could be underlying on the decrease in atherosclerotic plaque formation in ApoE-deficient mice fed with $1.8 \% \mathrm{P}$ diet.

This study has some limitations. At least, we cannot exclude the effects of high $\mathrm{P}$ intake on the development of atherosclerosis other than that on monocytes/macrophages. For instance, FGF23 may be a possible candidate. In $1.8 \% \mathrm{P}$ intake group, plasma FGF23 levels were very high compared with the other groups. FGF23 is responsible for $\mathrm{P}$ and vitamin D metabolisms and known as a predictor of chronic kidney disease. ${ }^{(33)}$ Recent studies have reported that FGF23 null mice were smaller in kidney size and occurred vascular calcification ${ }^{(34,35)}$ whereas FGF23 overexpression prevented progression of chronic kidney failure in rats. ${ }^{(36)}$ In this study, we could not investigate the effects of FGF23 on the development of atherosclerosis. To understand the effect of high $P$ loading on the development of atherosclerosis, further study must be needed.

\section{References}

1 Dhingra R, Sullivan LM, Fox CS, and et al. Relations of serum phosphorus and calcium levels to the incidence of cardiovascular disease in the community. Arch Intern Med 2007; 167: 879-885.

2 Tonelli M, Sacks F, Pfeffer M, Gao Z, Curhan G; Cholesterol And Recurrent Events Trial Investigators. Relation between serum phosphate level and cardiovascular event rate in people with coronary disease. Circulation 2005; 112: 2627-2633.

3 Jono S, McKee MD, Murry CE, and et al. Phosphate regulation of vascular smooth muscle cell calcification. Circ Res 2000; 87: E10-E17.

4 Giachelli CM. Vascular calcification mechanisms. J Am Soc Nephrol 2004; 15: 2959-2964.

5 Son BK, Kozaki K, Iijima K, and et al. Statins protect human aortic smooth muscle cells from inorganic phosphate-induced calcification by restoring

High $\mathrm{P}$ diet intake can induce endothelial dysfunction and must be a risk factor for atherosclerosis in normal condition. On the other hand, high $\mathrm{P}$ diet intake may prevent atherosclerosis formation in enhanced atherosclerogenic condition such as ApoEdeficient mice. Although we cannot fully understand the role of high $\mathrm{P}$ loading in vascular disease model such as ApoE-deficient mice at this time, the actual mechanism must be complicated. Epidemiologically, whereas hyperphosphatemia is positively associated with cardiovascular event in general population as well as CKD patients, ${ }^{(1,27)}$ it can be negatively associated with blood pressure. $^{(1,37)}$ We have no direct evidence, however, such contradictory effects of high $\mathrm{P}$ diet intake may help us to understand the complicated pathogenesis of cardiovascular disease in CKD patients.

In conclusion, prolonged excess $\mathrm{P}$ intake unexpectedly can ameliorate atherosclerosis formation in ApoE-deficient mice, at least in part, by changing the profile of peripheral inflammatory monocytes. To understand the role of high $\mathrm{P}$ diet intake in atherosclerogenesis in more detail, pathogenic conditions, the difference of tissue or organ, treatment period and dose, etc. should be considered in further investigations.

\section{Acknowledgments}

This work was supported by Grants-in-Aid for Scientific Research (B) (Y.T., E.T.), for Young Scientists (A) (Y.T.), Exploratory Research (Y.T.) from the Ministry of Education, Culture, Sports, Science, and Technology in Japan, and also was supported by the Kidney Foundation (JKFB09-15) (Y.T.). All authors declare no conflict of interest.

\section{Abbreviations}

ApoE

CKD

DMEM

ELISA

FCS

FGF23

IL-6

MCP-1

NO

$1,25-(\mathrm{OH})_{2} \mathrm{D}$

$\mathrm{P}$

tPAI-I

PBS

PTH

T-Cho

TG

TNF- $\alpha$

TUNEL apolipoprotein E

chronic kidney disease

Dulbecco's modified Eagle's medium

enzyme-linked immunosorbent assay

fetal bovine serum

fibroblast growth factor 23

interleukin-6

monocyte chemoattractant protein-1

nitric oxide

1,25-dihydroxyvitamin D

phosphate

tissue plasminogen activator inhibitor-1

phosphate buffered saline

parathyroid hormone

total cholesterol

triglycerides

tumor necrosis factor- $\alpha$

terminal deoxynucleotidyl transferase dUTP nick end labeling
Gas6-Axl survival pathway. Circ Res 2006; 98: 1024-1031.

6 Ishimura E, Taniwaki H, Tabata T, and et al. Cross-sectional association of serum phosphate with carotid intima-medial thickness in hemodialysis patients. Am J Kidney Dis 2005; 45: 859-865.

7 Onufrak SJ, Bellasi A, Shaw LJ, and et al. Phosphporus levels are associated with subclinical atherosclerosis in the general population. Atherosclerosis 2008; 199: 424-431.

8 Ruan L, Chen W, Srinivasan SR, Xu J, Toprak A, Berenson GS. Relation of serum phosphorus levels to carotid intima-media thickness in asymptomatic young adults (from the Bogalusa Heart Study). Am J Cardiol 2010; 106: 793797.

9 Ross R. Atherosclerosis—an inflammatory disease. N Engl J Med 1999; 340: $115-126$. 
10 Hamaguchi M, Seno T, Yamamoto A, and et al. Loxoprofen sodium, a nonselective NSAID, reduces atherosclerosis in mice by reducing inflammation. J Clin Biochem Nutr 2010; 47: 138-147.

11 Cai H, Harrison DG. Endothelial dysfunction in cardiovascular diseases: the role of oxidant stress. Circ Res 2000; 87: 840-844.

12 Heitzer T, Schlinzig T, Krohn K, Meinertz T, Münzel T. Endothelial dysfunction, oxidative stress, and risk of cardiovascular events in patients with coronary artery disease. Circulation 2001; 104: 2673-2678.

13 d'Uscio LV, Baker TA, Mantilla CB, and et al. Mechanism of endothelial dysfunction in apolipoprotein E-deficient mice. Arterioscler Thromb Vasc Biol 2001; 21: 1017-1022.

14 Kauser K, Cunha VD, Fitch R, Mallari C, Rubanyi GM. Role of endogenous nitric oxide in progression of atherosclerosis in apolipoprotein E-deficient mice. Am J Physiol Heart Circ Physiol 2000; 278: H1679-H1685.

15 Kuhlencordt PJ, Gyurko R, Han F, and et al. Accelerated atherosclerosis, aortic aneurysm formation, and ischemic heart dissease in apolipoprotein E/ endothelial nitric oxide synthase double-knockout mice. Circulation 2001; 104: $448-454$.

16 Shuto E, Taketani Y, Tanaka R, and et al. Dietary phosphorus acutely impairs endothelial function. J Am Soc Nephrol 2009; 20: 1504-1512.

17 Di Marco GS, Hausberg M, Hillebrand U, and et al. Increased inorganic phosphate induces human endothelial cell apoptosis in vitro. Am J Physiol Renal Physiol 2008; 294: F1381-F1387.

18 Meleti Z, Shapiro IM, Adams CS. Inorganic phosphate induces apoptosis of osteoblast-like cells in culture. Bone 2000; 27: 359-366.

19 Mansfield K, Rajpurohit R, Shapiro IM. Extracellular phosphate ions cause apoptosis of terminally differentiated epiphyseal chondrocytes. J Cell Physiol 1999; 179: 276-286.

20 Praticò D, Tangirala RK, Rader DJ, Rokach J, FitzGerald GA. Vitamin E suppresses isoprostane generation in vivo and reduces atherosclerosis in ApoE-deficient mice. Nat Med 1998; 4: 1189-1192.

21 Deckert V, Lizard G, Duverger N, and et al. Impairment of endotheliumdependent arterial relaxation by high-fat feeding in ApoE deficient mice: toward normalization by human ApoA-I expression. Circulation 1999; 100: $1230-1235$.

22 Liu J, Thewke DP, Su YR, Linton MF, Fazio S, Sinensky MS. Reduced macrophage apoptosis is associated with accelerated atherosclerosis in lowdensity lipoprotein receptor-null mice. Arterioscler Thromb Vasc Biol 2005; 25: $174-179$.

23 Tabas I. Consequences and therapeutic implications of macrophage apoptosis in atherosclerosis; the importance of lesion stage and phagocytic efficiency. Arterioscler Thromb Vasc Biol 2005; 25: 2255-2264.
24 Stoneman V, Braganza D, Figg N, and et al. Monocyte/macrophage suppression in CD11b diphtheria toxin receptor transgenic mice differentially affects atherogenesis and established plaques. Circ Res 2007; 100: 884-893.

25 Gautier EL, Huby T, Witztum JL, and et al. Macrophage apoptosis exerts divergent effects on atherogenesis as a function of lesion stage. Circulation 2009; 119: 1795-1804.

26 Geissmann F, Jung S, Littman DR. Blood monocytes consist of two principal subsets with distinct migratory properties. Immunity 2003; 19: 71-82.

27 Sunderkötter C, Nikolic T, Dillon MJ, and et al. Subpopulations of mouse blood monocytes differ in maturation stage and inflammatory response. $J$ Immunol 2004; 172: 4410-4417.

28 Tacke F, Randolph GJ. Migratory fate and differentiation of blood monocyte subsets. Immunology 2006; 211: 609-618.

29 Gosling J, Slaymaker S, Gu L, and et al. MCP-1 deficiency reduces susceptibility to atherosclerosis in mice that overexpress human apolipoprotein B. $J$ Clin Invest 1999; 103: 773-778.

30 Ohman MK, Wright AP, Wickenheiser KJ, Luo W, Russo HM, Eitzman DT. Monocyte chemoattractant protein-1 deficiency protects against visceral fat-induced atherosclerosis. Arterioscler Thromb Vasc Biol 2010; 30: 11511158.

31 Brånén L, Hovgaard L, Nitulescu M, Bengtsson E, Nilsson J, Jovinge $\mathrm{S}$. Inhibition of tumor necrosis factor- $\alpha$ reduces atherosclerosis in apolipoprotein E knockout mice. Arterioscler Thromb Vasc Biol 2004; 24: 2137 2142.

32 Eitzman DT, Westrick RJ, Xu Z, Tyson J, Ginsburg D. Plasminogen activator inhibitor-1 deficiency protects against atherosclerosis progression in the mouse carotid artery. Blood 2000; 96: 4212-4215.

33 Fliser D, Kollerits B, Neyer U, and et al. Fibroblast growth factor 23 (FGF23) predicts progression of chronic kidney disease: the Mild to Moderate Kidney Disease (MMKD) Study. J Am Soc Nephrol 2007; 18: 2600-2608.

34 Razzaque MS, St-Arnaud R, Taguchi T, Lanske B. FGF-23, vitamin D and calcification: the unholy triad. Nephrol Dial Transplant 2005; 20: 2032-2035.

35 Stubbs JR, Liu S, Tang W, and et al. Role of hyperphosphatemia and 1,25dihydroxyvitamin D in vascular calcification and mortality in fibroblastic growth factor 23 null mice. J Am Soc Nephrol 2007; 18: 2116-2124.

36 Kusano K, Saito H, Segawa H, Fukushima N, Miyamoto K. Mutant FGF23 prevents the progression of chronic kidney disease but aggravates renal osteodystrophy in uremic rats. J Nutr Sci Vitamminol (Tokyo) 2009; 55: 99-105.

37 Elliott P, Kesteloot H, Appel LJ, and et al. Dietary phosphorus and blood pressure-international study of macro- and micro-nutrients and blood pressure. Hypertension 2008; 51: 669-675. 